\title{
The Relevance of Indoor Air Quality in Hospital Settings: From an Exclusively Biological Issue to a Global Approach in the Italian Context
}

\author{
Gaetano Settimo $^{1}\left(\mathbb{D}\right.$, Marco Gola $^{2, * \mathbb{D}}$ and Stefano Capolongo ${ }^{2}$ \\ 1 Environment and Health Department, Istituto Superiore di Sanità, 00161 Rome, Italy; gaetano.settimo@iss.it \\ 2 Architecture, Built Environment and Construction Engineering Department, Politecnico di Milano, \\ 20133 Milan, Italy; stefano.capolongo@polimi.it \\ * Correspondence: marco.gola@polimi.it; Tel.: +39-02-2399-5140
}

Received: 2 March 2020; Accepted: 7 April 2020; Published: 8 April 2020

check for updates

\begin{abstract}
In the context of the architectures for health, it is an utmost priority to operate a regular and continuous updating of quality, efficacy, and efficiency's processes. In fact, health promotion and prevention take place through a proper management and design of healing spaces, in particular with regard to the most sensitive users. In recent decades, there has been increasing attention to indoor air quality in healthcare facilities. Nowadays, this issue must involve the implementation of a series of appropriate interventions, with a global approach of prevention and reduction of risk factors on users' health, which allows, in addition to a correct management of hospital settings, the realization of concrete actions. To date, in Italy, despite the indoor air being taken in consideration in numerous activities and studies aimed at understanding both building hygiene and environmental aspects, the greatest difficulty is strongly related to the absence of an integrated national policy. The scope of the paper is to underline the relevance of indoor air quality in hospital settings, highlighting the need of procedures, protocols, and tools for strengthening and improving interventions for health prevention, protection, and promotion of users.
\end{abstract}

Keywords: indoor air quality; healthcare settings; chemical and biological pollution; quality improvement; Italian context

\section{The Relevance of Built Environment: The Case of Healing Spaces}

In a strategic field such as care and assistance, diagnostics, prevention, research, training, and safeguarding of public health by architectures for health (hospitals, community health centers, clinics and outpatient centers, etc.), both public and private ones, it is utmost a priority to operate a regular and continuous updating of quality's processes, efficacy, and efficiency of healthcare practices. The approach should apply to its entirety with prevention techniques, training, health education, and promotion activities, in relation to the needs for the health protection of users (both patients, visitors, and staff), with particular attention to the most sensitive and vulnerable groups in hospital settings [1-4].

In this scenario the healthcare facilities, affected by the requirement of promoting greater innovation and improving the quality of services and processes, have given rise to a considerable amount of concrete actions and interventions, such as the improvement of staff's training, exceeding and updating the level of organizational, management, and structural standards of healthcare $[1,5,6]$. In several ways they contribute not only to the efficiency of territorial assistance and care [2] but also to the dissemination of the value of individual and public health prevention, with a broad perspective of citizens' health status, increasing as a consequence the years of life $[5,7,8]$.

In particular, in an Italian context, in order to correctly respond to the healthcare needs of the population, in the Health Pact for the years 2014-2016, signed by the Permanent Conference for the 
Relations between the State, the Regions, and the Autonomous Provinces, the state of health has been defined no longer as a source of cost, but as an economic and social investment, identifying a series of interventions to achieve and offer the best products for citizens' health and to promote the development of health and the competitiveness of the whole country [9]. This application has constituted a strategic and important opportunity to tackle some of the crucial and highly relevant issues of recent years with greater awareness, such as:

- $\quad$ improving the compulsory level of training and adequate preparation of healthcare and non-healthcare staff in prevention issues [10];

- the improvement of the investments for the technological and qualitative modernization of the healthcare infrastructures, so as to be able to operate effectively and efficiently (i.e., with a more careful attention to the correct selection of finishing and building materials, products, flexibility in use and ease use, and in the management of engineering plants, etc.);

- the enhancement of healthcare design and indoor air quality, which have a strong and direct impact on the quality of care [11,12];

- $\quad$ the humanization and hospitality of healing spaces $[13,14]$.

The methodologies for assessing the healthcare costs incurred by the various countries were developed by the Organization for Economic Cooperation and Development (OECD), in which 20\% of the total health expenditure, quantified in the report "Tackling Wasteful Spending on Health", does not contribute to a real improvement in populations' health status [15]. For this reason, several authors highlight the importance to promote health through design actions in the built environment (urban health strategies, healthy indoor spaces, etc.) [16-19].

Moreover, in relation to the Italian case, with the Decree no. 50/2015-Regulation for hospital assistance, structural, technological, qualitative, and quantitative standards relating to healthcare are aimed at promoting the expansion of the areas, increasing hospitable features of the environments, safety and security, and real and adequate quality of care, which must be adopted to create the conditions to produce benefits and high quality of the entire National Health System (NHS) network [2,20].

\section{Design and Management Aspects that Affect Indoor Air in Hospital Settings}

In this evolutionary context, there has been growing attention to indoor air quality's issue in healthcare facilities, which, in order to satisfy primarily the requests of patients, healthcare users and workers, administrative and non-administrative staff, etc., have been affected to a series of new adjustments and design approaches (i.e., configuration and rationalization of spaces and flows, the use of specific products and materials, etc.) [21,22], structural and functional actions (i.e., requalification, restructuring, energy efficiency improvement, etc.) [23], engineering plants' system (i.e., optimizing the performance of the centralized heating and cooling systems, energy performances, etc.), [24] and management strategies (i.e., the correct daily management of the ventilations systems, the reduction of costs, accounting for consumption, etc.) [25], with the aim of expanding the services supplied, the quality of healthcare services, obtaining greater organizational and working flexibility, and attempting to reduce the economic costs of healthcare facilities [26]. Gola et al. have highlighted the factors that mostly affect a healing space, as Figure 1 synthetizes [40].

In all these healthcare environments for different needs, the healthcare and technical and administrative staffs, and the users (caregivers, elderly people, children, volunteers, students, visitors, outsourcing services' staffs, maintenance workers and suppliers, etc.)—-some of them with reduced mobility, too-interact, stay, live, and work [27,28]. For this reason, specific prevention measures are necessary, considering the exposure of key actors (from the users to hospital staff), whose roles, knowledge and background, motivations, and individual relationships have changed and evolved, becoming increasingly an informed, active, and willing participation to collaborate for improving the environments' quality, services, and treatments. Their exposure takes on particular significance and importance both for the vulnerabilities of the users (i.e., patients with various pathologies, with an 
acute health status, with different immune responses, people with disabilities elderly, etc.), and for the times of permanence in the hospital [29-33].

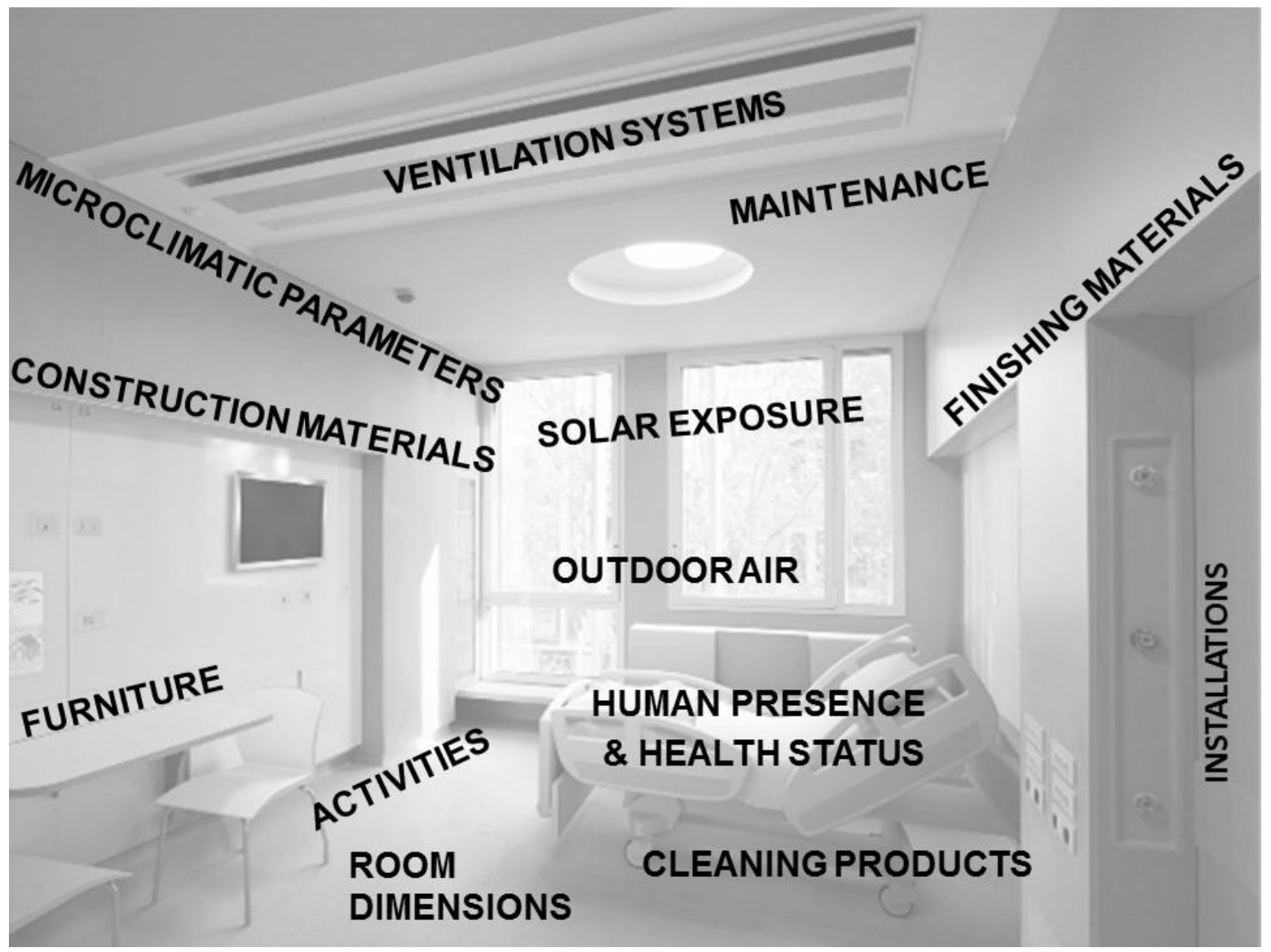

Figure 1. Factors that affect hospital environments.

In the specific case of the activities carried out in the healthcare facilities, it is essential to consider the close relationships between the behaviors and activities of medical e and technical-administrative staffs, and the different ones of patients, visitors, volunteers, students, professionals of external companies (i.e., cleaning, maintenance, suppliers, etc.), the quality of the spaces, and daily relationships with the organizational and management procedures of functional processes, that define the complex scenario of activities to be delivered [34,35]. The use of technological systems designed to perform and satisfy the various tasks in the best economic conditions, the technical furnishings, the level of use, the ordinary and extraordinary cleaning and sanitization activities (providing targeted actions according to the health status and the type of risk of patients, with different levels of contamination, and with microbiological monitoring), the maintenance, the procedures, and the organic management of the multiple routine prevention activities implemented and shared within the spaces, are all factors that contribute significantly to indoor air quality, and the health (this is even more concrete in view of the emergency period for SARS-CoV-2 virus that currently the population is experiencing) and satisfaction of all those users who attend the healing spaces $[24,25,35]$.

In general, these interventions and initiatives have been adopted to address the significant change in healthcare needs, which affects the growth of requests for services and diagnostic treatments, as well as new fields of assistance and research, which require greater functionality of spaces, a reduction in the average length of hospitalization, the occupancy rate of beds, and inter-regional flows of healthcare mobility, overcoming social and territorial inequalities [36,37]. 
Specifically, on the operational level as regards the interventions carried out, it is necessary to highlight how often the choices of products and construction materials (i.e., paints, varnishes, etc.), finishing, (i.e., adhesives, silicones, etc.), furniture components (i.e., decors, curtains, etc.), products for cleaning and detergents for daily use, products for ordinary (methods and frequency that independently must always be adapted to the use of the area, to the flows of inpatients or medical staff, visitors, etc.) and extraordinary sanitization (i.e., use of more or less products concentrated, or not specific for cleaning surfaces, etc.), as well as engineering plant's management and maintenance activities (i.e., various air conditioning systems and centralized controlled mechanical ventilation systems), etc. were carried out in a disordered manner, without an adequate assessment of the emission behavior of pollutants from the materials and products used (i.e., VOCs-volatile organic compounds-and other substances emissions). In fact, the specificity and the protective value that the environments must respond to specific environmental conditions of use (i.e., temperature, relative humidity, air changes, etc.), the presence of patients, healthcare users, temporary visitors, volunteers, activities carried out by healthcare staff and not, and hygienic conditions of the environments depending on the health status, the type or risk of patients or, in general, of the daily flows (i.e., presence of microbial and fungal communities with a capacity for persistence, variability of concentration, and diversity in healthcare environments, which can generate an extension of the length of hospitalization stay, additional diagnostic and/or therapeutic interventions and additional costs, etc.) [38,39].

\section{Chemical and Biological Concentrations in Indoor Air in Healthcare Environments}

It should be underlined that, until a few years ago, in Italy, most of the activities and direct and indirect interventions of prevention and training were limited exclusively to select and identified healthcare environments with specific professional exposure to: chemical and biological agents (i.e., monitoring in the air of anesthetic gases in operating rooms, in laboratories dedicated to the preparation and administration of antiblastic drugs, in premises or areas of chemical sterilization, in histology and pathological anatomy departments for use of preservatives or disinfectants (i.e., formaldehyde, waste storage, and transport activities, etc.); ergonomic and physical factors (i.e., patient movement, sudden movements with efforts, critical or prolonged working posture, and in the administrative offices related to the workplace, etc.); video terminals (i.e., in administrative offices, call centers, back offices, departments, etc.); accidents (i.e., falls, etc.); psychosocial (i.e., excessive workload, stress and satisfaction levels, etc.); microclimatic factors such as temperature, relative humidity, air changes (both in health and administrative areas, etc.); implementation of programs of multidisciplinary hygiene surveillance and control such as those developed by the hospital infection committees for the control of infections, of the Supervisory Commissions, composed of a group of dedicated professional figures and with guidelines and protocols for the control of pollutants of biological origin (provided in compliance with ministerial acts), in order to prevent patient-related and non-healthcare staff and non-healthcare-related infections, which have always been a major concern for all hospitals [40-45].

For this reason, these aspects are increasingly integral components of the quality of services, therapies, healthcare services, activities and training, and information plans continuously provided, contributing to obtaining an effective and adequate indoor air quality, which responds to the main references elaborated for some time by the World Health Organization (WHO), and which currently constitute a valuable contribution worldwide.

In general, although the biological pollutants are constantly under analysis, they have already been studied and investigated by several research groups, and several countries have defined guidelines and very detailed protocols (that need to be improved more and more), such as Legionella, etc. [32,46].

Unlike the activities on biological compounds, investigations or monitoring activities of indoor air quality dedicated to the presence (or assessment) of the concentrations of chemical pollutants also to other environments have been carried out only recently and marginally, in some functional areas and environments of the hospital. Never before have such monitoring activities been brought to the attention of management by users, healthcare staff, etc., who complain of uncomfortable circumstances 
while living and working in the hospital settings or in carrying out their work activities that do not involve the use of chemical or biological agents $[45,46]$. Often at the operational level, these are requested that usually occur for complaints to situations related to an inadequate air exchange, the presence of new furnishings, the change of the room, during maintenance or renovation activities in specific areas and/or in punctual rooms, when the intended uses vary, when using cleaning and detergent products, or due to the inadequate or incorrect operation of the ventilation systems, etc. [45].

Therefore nowadays, this must entail the implementation of a series of appropriate and organized interventions (not limited to single and specific actions), with a global approach of prevention and reduction of risk factors on the health of all users, which allow, in addition to a correct management of the various environments of healthcare facilities, the realization of concrete actions on indoor air quality according to the priority principles and guidelines identified by WHO [47] and in part already listed as goals in various European and international programs of the prevention measures [12].

With particular attention to chemical pollutants, an examination of the current situation in the European Union (EU) shows that some Member States, such as France, Belgium, Finland, Portugal, Poland, and Lithuania have fully entered the quality of the indoor air in their national legislations with quantitative values (reference values, guidelines, etc.), and with practical guidelines which contain indications for the control, self-assessment sheets for identifying potential indoor sources (or close to the facilities), and the procedures for the development of indoor air monitoring, which are in many cases in line with the current WHO values published in 2009 and 2010 on the basis of the main scientific evidences [12].

In these countries, compliance with the legal requirements and the correct application of practical protocols remain one of the fundamental points for achieving good indoor air quality in the various healthcare environments [48]. In particular, France has foreseen a series of specific interventions including mandatory monitoring of indoor air quality in healthcare facilities as early as 2023 [49].

Until today, in Italy, despite being the quality of indoor air subjected to numerous activities and investigations aimed at understanding both the environmental and hygiene aspects, the greatest difficulty remains the absence of an integrated national policy about indoor air quality, with specific legislative references, which report the national references (i.e., guide values, references, etc.) and the rules for the data analysis of the results, and with documents that list the recommendations for an adequate management and evaluation of indoor air quality [50]. In the absence of national references, it is possible to use those present in the WHO documents related to indoor air quality or those in the legislation of other European countries or, by analogy, to other standards such as those relating to the ambient air for which specific legislative references have been issued on a limited number of pollutants, etc. [51].

There is no doubt that the current system of health prevention and protection laws has led to a confusion of language and knowledge that indeed has often confused and disoriented the practitioners, engaged in various capacities in the programs and evaluations in these environments and structures [37]. In this process of approach and strengthening of prevention actions, it is necessary to bring about a concrete harmonization, revision, innovation, updating and expansion on specific aspects, also to current standards [52]).

The aims and scope are to provide the procedures and tools necessary to strengthen, optimize, and improve interventions for the prevention, protection, and promotion of the health of users in healthcare environments that represent one of the priority objectives of the NHS's strategy in the prevention programs, with monitoring activities within the healing spaces [38,53].

Additionally, with regard to biological pollutants, although there are recommendations from international agencies and institutions, there are no legislative values or standards for the microbiological parameters of indoor air quality due to the difficulties encountered in correlating the data of the microbiological tests with those of the epidemiological investigations [46]. 


\section{Future Perspectives}

In conclusion, hospital facilities are complex constructions, with very different needs, users, and requirements compared to other building facilities, and they work $24 / 7$, all year long. For this reason, every action should be assessed in relation to their performances and the aim to interrupt medical activities as little as possible.

It is clever that indoor air quality is a very broad topic in which any variable can affect the performances of air in indoor environments both in biological and chemical terms, as one of the goals of UN 2030-United Nations Sustainable Development. As several authors states, adequate design and management strategies, in relation to different procedures, can decrease or increase the quality performances of the healthcare environments.

The Scientific Community should continue to investigate the issue, define smart and efficient procedures, protocols for monitoring and tools, instrumentations for the investigations, etc. for strengthening and improving interventions, and guaranteeing protection and promotion of users. The new challenge should investigate the correlations between the chemical and biological pollutants and their effects in indoor air and the quality of the healthcare facility.

Author Contributions: Conceptualization, G.S. and M.G.; writing-original draft preparation, M.G. and G.S.; writing-review and editing, M.G.; supervision, S.C. All authors have read and agreed to the published version of the manuscript.

Funding: This research received no external funding.

Conflicts of Interest: The authors declare no conflict of interest.

\section{References}

1. Brambilla, A.; Buffoli, M.; Capolongo, S. Measuring hospital qualities. A preliminary investigation on Health Impact Assessment possibilities for evaluating complex buildings. Acta Bio-Med. Atenei Parm. 2019, 90, 54-63.

2. Capolongo, S.; Mauri, M.; Peretti, G.; Pollo, R.; Tognolo, C. Facilities for Territorial Medicine: The experiences of Piedmont and Lombardy Regions. Technè 2015, 9, 230-236.

3. Settimo, G. Residential indoor air quality: Significant parameters in light of the new trends. Ig. Sanità Pubblica 2012, 68, 136-138.

4. Azara, A.; Dettori, M.; Castiglia, P.; Piana, A.; Durando, P.; Parodi, V.; Salis, G.; Saderi, L.; Sotgiu, G. Indoor Radon Exposure in Italian Schools. Int. J. Environ. Res. Public Health 2018, 15, 749. [CrossRef] [PubMed]

5. Brambilla, A.; Capolongo, S. Healthy and sustainable hospital evaluation-A review of POE tools for hospital assessment in an evidence-based design framework. Buildings 2019, 9, 76. [CrossRef]

6. Odone, A.; Bossi, E.; Gaeta, M.; Garancini, M.P.; Orlandi, C.; Cuppone, M.T.; Signorelli, C.; Nicastro, O.; Zotti, C.M. Risk Management in healthcare: Results from a national-level survey and scientometric analysis in Italy. Acta Biomed. 2019, 90, 76-86.

7. Capobussi, M.; Tettamanti, R.; Marcolin, L.; Piovesan, L.; Bronzin, S.; Gattoni, M.E.; Polloni, I.; Sabatino, G.; Tersalvi, C.A.; Auxilia, F.; et al. Air Pollution Impact on Pregnancy Outcomes in Como, Italy. J. Occup. Environ. Med. 2016, 58, 47-52. [CrossRef]

8. Vonci, N.; De Marco, M.F.; Grasso, A.; Spataro, G.; Cevenini, G.; Messina, G. Association between air changes and airborne microbial contamination in operating rooms. J. Infect. Public Health 2019, 12, 827-830. [CrossRef]

9. Signorelli, C.; Odone, A.; Ricciardi, W.; Lorenzin, B. The social responsibility of public health: Italy's lesson on vaccine hesitancy. Eur. J. Public Health 2019, 29, 1003-1004. [CrossRef]

10. Gianfredi, V.; Grisci, C.; Nucci, D.; Parisi, V.; Moretti, M. Communication in health. Recenti Progress. Med. 2018, 109, 374-383.

11. Moreno-Rangel, A.; Sharpe, T.; Musau, F.; McGill, G. Field evaluation of a low-cost indoor air quality monitor to quantify exposure to pollutants in residential environments. J. Sens. Sens. Syst. 2018, 7, 373-388. [CrossRef] 
12. Settimo, G. Existing guidelines in indoor air quality: The case study of hospital environments. In Indoor Air Quality in Healthcare Facilities, 1st ed.; Capolongo, S., Settimo, G., Gola, M., Eds.; Springer Public Health: New York City, NY, USA, 2017; pp. 13-26.

13. Buffoli, M.; Bellini, E.; Bellagarda, A.; di Noia, M.; Nickolova, M.; Capolongo, S. Listening to people to cure people: The LpCp-tool, an instrument to evaluate hospital humanization. Ann. Ig. 2014, 26, 447-455. [PubMed]

14. Bosia, D.; Marino, D.; Peretti, G. Health facilities humanisation: Design guidelines supported by statistical evidence. Ann. Dell'Istituto Super. Sanita 2016, 52, 33-39.

15. Smith, D.; Alverdy, J.; An, G.; Coleman, M.; Garcia-Houchins, S.; Green, J.; Keegan, K.; Kelley, S.T.; Kirkup, B.C.; Kociolek, L.; et al. The hospital microbiome project: Meeting report for the 1st hospital microbiome project workshop on sampling design and building science measurements. Stand. Genomic. Sci. 2013, 8, 112-117. [CrossRef] [PubMed]

16. Rebecchi, A.; Buffoli, M.; Dettori, M.; Appolloni, L.; Azara, A.; Castiglia, P.; D’Alessandro, D.; Capolongo, S. Walkable environments and healthy urban moves: Urban context features assessment framework experienced in Milan. Sustainability 2019, 11, 2778. [CrossRef]

17. Congiu, T.; Sotgiu, G.; Castiglia, P.; Azara, A.; Piana, A.; Saderi, L.; Dettori, M. Built Environment Features and Pedestrian Accidents: An Italian Retrospective Study. Sustainability 2019, 11, 1064. [CrossRef]

18. Rebecchi, A.; Boati, L.; Oppio, A.; Buffoli, M.; Capolongo, S. Measuring the expected increase in cycling in the city of Milan and evaluating the positive effects on the population's health status: A Community-Based Urban Planning experience. Ann. Ig. 2016, 28, 381-391.

19. D'Alessandro, D.; Arletti, S.; Azara, A.; Buffoli, M.; Capasso, L.; Cappuccitti, A.; Casuccio, A.; Cecchini, A.; Costa, G.; De Martino, A.M.; et al. Strategies for Disease Prevention and Health Promotion in Urban Areas: The Erice 50 Charter. Ann. Ig. 2017, 29, 481-493. [CrossRef]

20. Campanella, P.; Azzolini, E.; Izzi, A.; Pelone, F.; De Meo, C.; La Milia, D.; Specchia, M.; Ricciardi, W. Hospital efficiency: How to spend less maintaining quality? Ann. Dell'Istituto Super. Sanita 2017, 53, 46-53.

21. Gray, W.A.; Vittori, G.; Guenther, R.; Vernon, W.; Dilwali, K. Leading the way: Innovative sustainable design guidelines for operating healthy healthcare buildings. In Proceedings of the ISIAQ-10th International Conference on Healthy Buildings, Curran Associates, Red Hook, NY, USA, 12 July 2012; pp. 1212-1217.

22. Setola, N.; Borgianni, S. Designing Public Spaces in Hospitals; Taylor and Francis Inc.: London, UK, 2016.

23. Pati, D.; Park, C.-S.; Augenbroe, G. Facility maintenance performance perspective to target strategic organizational objectives. J. Perform. Constr. Facil. 2010, 24, 180-187. [CrossRef]

24. Joppolo, C.M.; Romano, F. HVAC System Design in Health Care Facilities and Control of Aerosol Contaminants: Issues, Tools and Experiments. In Indoor Air Quality in Healthcare Facilities, 1st ed.; Capolongo, S., Settimo, G., Gola, M., Eds.; Springer Public Health: New York, NY, USA, 2017; pp. 83-94.

25. Moscato, U.; Borghini, A.; Teleman, A.A. HVAC Management in Health Facilities. In Indoor Air Quality in Healthcare Facilities, 1st ed.; Capolongo, S., Settimo, G., Gola, M., Eds.; Springer Public Health: New York, NY, USA, 2017; pp. 95-106.

26. Gola, M.; Settimo, G.; Capolongo, S. Indoor air in healing environments: Monitoring chemical pollution in inpatient rooms. Facilities 2019, 37, 600-623. [CrossRef]

27. Carducci, A.L.; Fiore, M.; Azara, A.; Bonaccorsi, G.; Bortoletto, M.; Caggiano, G.; Calamusa, A.; De Donno, A.; De Giglio, O.; Dettori, M.; et al. Environment and health: Risk perception and its determinants among Italian university students. Sci. Total Environ. 2019, 691, 1162-1172. [CrossRef] [PubMed]

28. Mosca, E.I.; Capolongo, S. Towards a universal design evaluation for assessing the performance of the built environment. In Transforming Our World through Design, Diversity and Education, 1st ed.; Craddock, G., Doran, C., McNutt, L., Rice, D., Eds.; Springer Studies in Health Technology and Informatics: Cham, Switzerland, 2018; Volume 256, pp. 771-779.

29. Gola, M.; Mele, A.; Tolino, B.; Capolongo, S. Applications of IAQ Monitoring in International Healthcare Systems. In Indoor Air Quality in Healthcare Facilities, 1st ed.; Capolongo, S., Settimo, G., Gola, M., Eds.; Springer Public Health: New York, NY, USA, 2017; pp. 27-39.

30. Borghini, A.; Poscia, A.; Bosello, S.; Teleman, A.A.; Bocci, M.; Iodice, L.; Ferraccioli, G.; La Milìa, D.; Moscato, U. Environmental pollution by benzene and PM10 and clinical manifestations of systemic sclerosis: A correlation study. Int. J. Environ. Res. Public Health 2017, 14, 1297. [CrossRef] [PubMed] 
31. La Milia, D.; Vincenti, S.; Fiori, B.; Pattavina, F.; Torelli, R.; Barbara, A.; Wachocka, M.; Moscato, U.; Sica, S.; Amato, V.; et al. Monitoring of particle environmental pollution and fungal isolations during hospital building-work activities in a hematology ward. Mediterr. J. Hematol. Infect. Dis. 2019, 11, e2019062. [PubMed]

32. Sotgiu, G.; Are, B.M.; Pesapane, L.; Palmieri, A.; Muresu, N.; Cossu, A.; Dettori, M.; Azara, A.; Mura, I.I.; Cocuzza, C.; et al. Nosocomial transmission of carbapenem-resistant Klebsiella pneumoniae in an Italian university hospital: A molecular epidemiological study. J. Hosp. Infect. 2018, 99, 413-418. [CrossRef]

33. Harvey, T.E., Jr.; Pati, D. Keeping watch. Design features to aid patient and staff visibility. Health Facil. Manag. 2012, 25, 27-31.

34. Leung, M.; Chan, A.H.S. Control and management of hospital indoor air quality. Med. Sci. Monit. 2006, 12, SR17-SR23.

35. Gola, M.; Settimo, G.; Capolongo, S. Chemical Pollution in Healing Spaces: The Decalogue of the Best Practices for Adequate Indoor Air Quality in Inpatient Rooms. Int. J. Environ. Res. Public Health 2019, 16, 4388. [CrossRef]

36. Mauri, M. The future of the hospital and the structures of the NHS. Technè 2015, 9, 27-34.

37. Signorelli, C.; Fara, G.M.; Odone, A.; Zangrandi, A. The reform of the Italian Constitution and its possible impact on public health and the National Health Service. Health Policy 2017, 121, 90-91. [CrossRef]

38. Gola, M.; Settimo, G.; Capolongo, S. Indoor Air Quality in Inpatient Environments: A Systematic Review on Factors that Influence Chemical Pollution in Inpatient Wards. J. Healthc. Eng. 2019, 8358306. [CrossRef] [PubMed]

39. Śmiełowska, M.; Marć, M.; Zabiegała, B. Indoor air quality in public utility environments-A review. Environ. Sci. Pollut. Res. 2017, 24, 11166-11176. [CrossRef] [PubMed]

40. D'Amico, A.; Fara, G.M. The need to develop a multidisciplinary expertise for the microbiological safety of operating theatres. Ann. Ig. 2016, 28, 379-380. [PubMed]

41. Montagna, M.T.; Cristina, M.L.; De Giglio, O.; Spagnolo, A.M.; Napoli, C.; Cannova, L.; Deriu, M.G.; Delia, S.A.; Giuliano, A.; Guida, M.; et al. Serological and molecular identification of Legionella spp. isolated from water and surrounding air samples in Italian healthcare facilities. Environ. Res. 2016, 146, 47-50. [CrossRef] [PubMed]

42. ISIAQ (International Society of Indoor Air Quality and Climate). Review on Indoor Air Quality in Hospitals and Other Health Care Facilities; International Society of Indoor Air Quality and Climate: Philadelphia, PA, USA, 2003; Volume 43.

43. Ardoino, I.; Zangirolami, F.; Iemmi, D.; Lanzoni, M.; Cargnelutti, M.; Biganzoli, E.; Castaldi, S. Risk factors and epidemiology of Acinetobacter baumannii infections in a university hospital in Northern Italy: A case-control study. Am. J. Infect. Control 2016, 44, 1600-1605. [CrossRef]

44. Castaldi, S.; Bevilacqua, L.; Arcari, G.; Cantù, A.P.; Visconti, U.; Auxilia, F. How appropriate is the use of rehabilitation facilities? Assessment by an evaluation tool based on the AEP protocol. J. Prev. Med. Hyg. 2010, 51, 116-120.

45. Settimo, G.; Bonadonna, L.; Gherardi, M.; di Gregorio, F.; Cecinato, A. Qualità dell'aria negli ambienti sanitari: Strategie di monitoraggio degli inquinanti chimici e biologici. Rapporti ISTISAN 2019, 19/17, 1-55.

46. Bonadonna, L.; de Grazia, M.C.; Capolongo, S.; Casini, B.; Cristina, M.L.; Daniele, G.; D’Alessandro, D.; De Giglio, O.; Di Benedetto, A.; Di Vittorio, G.; et al. Water safety in healthcare facilities. The Vieste Charter. Ann. Ig. 2017, 29, 92-100.

47. WHO. Guidelines for Indoor Air Quality: Selected Pollutants, 1st ed.; World Health Organization: Copenhagen, Denmark, 2010.

48. Oddo, A. The intervention of the judicial system in order to maximise the prevention of chemical risk in operating theatres and to put personal health and safety first. Med. Lav. 2016, 107, 5-20.

49. ANSES. Air Intérieur: Valeurs Guides; Agence Nationale de Sècuritè Sanitaire: Paris, France, 2011.

50. Settimo, G.; D'Alessandro, D. European community guidelines and standards in indoor air quality: What proposals for Italy. Epidemiol. Prev. 2014, 38, 36-41.

51. Viviano, G.; Settimo, G. Air quality regulation and implementation of the European Council Directives. Ann. Dell'Istituto Super. Sanita 2003, 39, 343-350. 
52. Oddo, A. The contribution of technology and the forefront role of technical measures in the prevention of infection risk in the healthcare sector. Med. Lav. 2016, 107, 21-30. [PubMed]

53. Settimo, G.; Gola, M.; Mannoni, V.; De Felice, M.; Padula, G.; Mele, A.; Tolino, B.; Capolongo, S. Assessment of Indoor Air Quality in Inpatient Wards. In Indoor Air Quality in Healthcare Facilities, 1st ed.; Capolongo, S., Settimo, G., Gola, M., Eds.; Springer Public Health: New York, NY, USA, 2017; pp. 107-118.

(C) 2020 by the authors. Licensee MDPI, Basel, Switzerland. This article is an open access article distributed under the terms and conditions of the Creative Commons Attribution (CC BY) license (http://creativecommons.org/licenses/by/4.0/). 